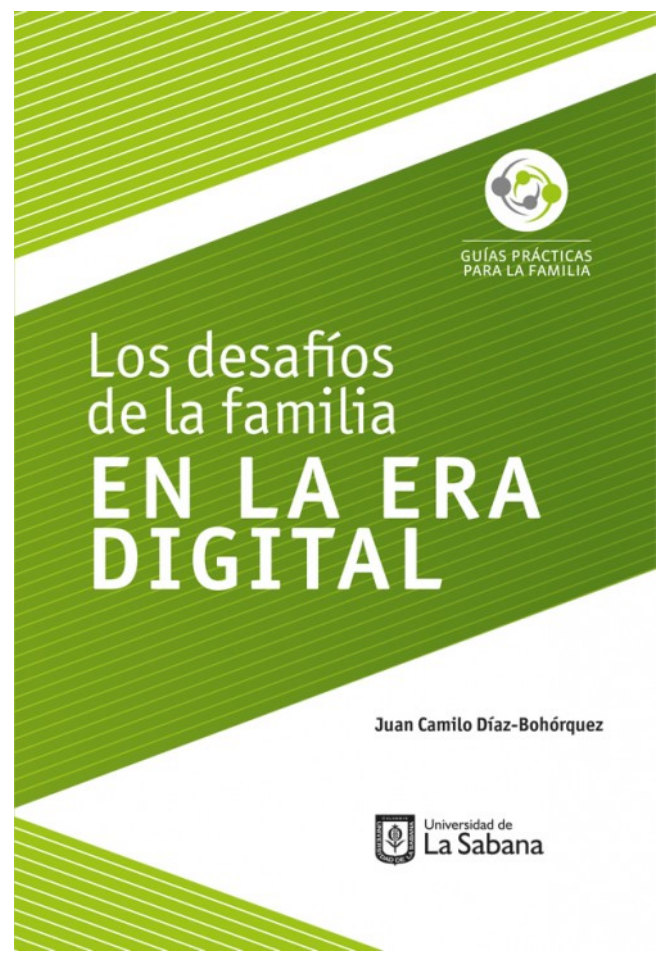

\title{
LOS DESAFÍOS DE LA FAMILIA EN LA ERA DIGITAL
}

Por: Juan Camilo Díaz Bohórquez

Formato: Impreso

ISBN: 978-958-12-0467-0

Facultad: Instituto de la Familia

Colección: Guías prácticas para la Familia

DOI: https://doi.org/10.5294/978-958-12-0467-0

Idioma: Español

Precio en dólares: USD $\$ 7,00$

Número de páginas: 76

Palabras clave: Educación familiar, Familia, Tecnología educativa

$\$ 20.000$

\section{Reseña del Producto}

Uno de los grandes desafíos educativos que tiene por delante la familia en cabeza de los padres es formar a sus niños para que hagan uso seguro, responsable y constructivo de las nuevas tecnologías de la información y las comunicaciones. No obstante, es una tarea pendiente. ¿Por qué? Durante mucho tiempo se ha arraigado de manera progresiva un concepto: el de chip tecnológico. Este consiste en creer que los niños y adolescentes manipulan los aparatos tecnológicos más fácil que nosotros gracias a una carga en su ADN especial, superior y diferente. ¡Y realmente lo creemos! Hemos llegado a creer que niños y adolescentes, por el simple hecho de serlos, cuentan con una especie de "competencia" digital, una especie de predisposición para el uso más eficiente de la tecnología. Sin embargo, eso no es tan cierto.

\section{Información Adicional}

\author{
Peso: $1 \mathrm{~kg}$
}

Tamaño: $17 \times 24 \times 2 \mathrm{~cm}$

Sku: 9789581204670

Código topografico: 372.358

\section{Tabla de contenido}

\section{INTRODUCCIÓN}

LA FAMILIA Y SU ROL EDUCATIVO ANTE LAS NUEVAS TECNOLOGÍAS

¿Por qué la familia debe educar en estos temas de tecnología?

¿La tecnología es buena o mala?

¿Es segura la tecnología para nuestros hijos?

¿Se puede ser una familia digital?

NIÑOS Y ADOLESCENTES ANTE LAS NUEVAS TECNOLOGÍAS

¿Los niños entienden todo lo que ven, escuchan y navegan? 
¿Son los niños de ahora "nativos digitales"?

¿Los niños vienen con un "chip tecnológico"?

¿Para qué usan niños y adolescentes la tecnología?

¿Hay una edad adecuada para que los niños comiencen a usar tecnología?

¿Existen estrategias para un uso adecuado de la tecnología?

¿Cuáles son las recomendaciones básicas para un uso seguro de la tecnología?

INTERNET Y LAS REDES SOCIALES

¿Existe una edad adecuada para que los niños accedan a Internet?

¿Existe una edad mínima para que los niños usen redes sociales?

¿Qué riesgos existen en las redes sociales y en Internet?

¿Qué es la pornografía infantil en línea?

¿Qué es el grooming?

¿Qué es el sexting?

¿Qué es el ciberacoso?

¿Qué es el oversharing?

¿Qué es el sharent?

¿Qué es el vamping?

¿Qué podemos hacer para que nuestros hijos no corran riesgos?

LOS VIDEOJUEGOS

¿Tienen algo de positivo los videojuegos?

¿Cuáles son sus aspectos negativos?

¿Qué puedo hacer para que los niños usen de forma responsable los videojuegos?

¿Cómo puedo saber si existe una adicción a los videojuegos?

LOS CELULARES

¿Qué debo tener en cuenta antes de comprarle un celular a mi hijo?

¿Qué riesgos existen asociados al uso de celular?

¿Qué puedo hacer para que lo usen de forma adecuada?

LA TELEVISIÓN

¿Es buena o mala la televisión?

¿Puede la televisión educar?

¿Existen planes de acción para el uso adecuado de la televisión?

RECOMENDACIONES FINALES

SITIOS WEB DE AYUDA

APLICACIONES

REFERENCIAS 